\title{
COMPACTAÇÃO DE UM CAMBISSOLO CAUSADA POR MÁQUINAS DE COLHEITA FLORESTAL ESPACIALIZADA COM GEOESTATÍSTICA
}

\author{
Jean Alberto Sampietro ${ }^{1}$, Eduardo da Silva Lopes ${ }^{2 *}$ \\ ${ }^{1}$ Universidade do Estado de Santa Catarina, Departamento de Engenharia Florestal, Lages, Santa Catarina, Brasil - jean.sampietro@udesc.br \\ ${ }^{2}$ Universidade Estadual do Centro-Oeste, Departamento de Engenharia Florestal, Irati, Paraná, Brasil - eslopes@irati.unicentro.br \\ Recebido para publicação: 24/07/2014 - Aceito para publicação: 10/05/2016
}

\begin{abstract}
Resumo
Este trabalho objetivou avaliar o impacto e a extensão em que a resistência à penetração (RP) de um Cambissolo Húmico é afetada pelo tráfego de máquinas de colheita da madeira em povoamentos de Pinus taeda L., utilizando métodos geoestatísticos. O estudo foi conduzido em áreas de uma empresa florestal localizada em Santa Catarina. Os tratamentos avaliados advieram da simulação de diferentes intensidades de tráfego. Foram realizadas leituras de RP nas trilhas de passagem dos rodados das máquinas e transversalmente em intervalos de 0,25 até $1,00 \mathrm{~m}$ e entre rodados, perfazendo uma malha de $5 \times 20 \mathrm{~m}$, sendo 55 pontos por tratamento e 330 no total, com dados obtidos em intervalos de $0,01 \mathrm{~m}$ até $0,80 \mathrm{~m}$ de profundidade. Os dados foram avaliados por estatística descritiva e ajustaram-se modelos de semivariogramas para análise da dependência espacial e posterior realização de krigagem ordinária. Houve grande amplitude e variação da RP e predominância de ajuste de semivariogramas do tipo gaussiano, com forte grau de dependência espacial, de 0,774 a 0,929, e alcance variando de 0,83 a $2,12 \mathrm{~m}$. Os métodos geoestatísticos permitiram determinar a extensão dos efeitos do tráfego, podendo servir de subsídio para melhoria no manejo do solo e planejamento das operações florestais.

Palavras-chave: Mecanização florestal; resistência à penetração; variabilidade espacial.
\end{abstract}

\begin{abstract}
Compaction of a cambisol caused by forest harvesting machines with spatialized geostatistics. The objective of this study was to evaluate the impact and the extent which penetration resistance (PR) of a Humic Cambisol (HC) is affected by traffic of timber harvesting machines in stands of Pinus taeda L., using geostatistics methods. The study was conducted in areas of the forestry company located in the Santa Catarina State, Brazil. The treatments were derived from simulation of different machines traffics intensities. The soil penetration resistance (PR) measures were taken in wheel tracks trails and in horizontal intervals of 0.25 up to $1.00 \mathrm{~m}$, and in between the tracks, making a grid of $5 \times 20 \mathrm{~m}$, with 55 points per treatment and 330 in total, being the data collected at intervals of 0.01 up to $0.80 \mathrm{~m}$ of depth. Data were analyzed with descriptive statistics and were adjusted semivariogram models for the spatial dependence analysis. The results showed a great range and variation of compaction dates. Gaussian models predominated in adjusted variogram models, with strong spatial dependence degree, from 0.774 to 0.929 , and range ranged from 0.83 to $2.12 \mathrm{~m}$. The geostatistics methods allowed to determine the extent of the traffic effects, and may provide support for improvement soil management and planning of forest operations.

Keywords: Forest mechanization; penetration resistance; spatial variability.
\end{abstract}

\section{INTRODUÇÃO}

Durante as operações de colheita da madeira, as máquinas trafegam várias vezes sobre o mesmo local dentro do povoamento florestal, podendo causar a compactação do solo e provocar alterações nas suas propriedades físicas, químicas e biológicas, afetando o seu potencial produtivo (LOPES et al., 2006). Tal efeito pode ocorrer em todo o povoamento e não apenas nas áreas próximas às trilhas de passagem das máquinas, ocasionando o impedimento mecânico ao crescimento radicular e resultando em menor volume de solo explorado, menor absorção de água e nutrientes e, consequentemente, menor desenvolvimento das plantas nas rotações futuras.

A compactação do solo ocorre quando as forças mecânicas impostas pelo tráfego das máquinas são superiores à capacidade de suporte do solo. Em consequência, a estrutura do solo é modificada, havendo aproximação das partículas, com redução no volume por elas ocupado, o que traz incremento na densidade e resistência mecânica à penetração de raízes, redução do volume e continuidade dos poros, refletindo nos fluxos de solução e ar do solo (REICHERT et al., 2010). Dessa forma, as plantas são submetidas a situações adversas ao seu desenvolvimento, devido, principalmente, às limitações apresentadas ao estabelecimento do sistema radicular, podendo haver comprometimento da produção de madeira nas áreas de reflorestamento.

Entre os fatores que afetam o nível de compactação do solo, o número de passadas das máquinas é considerado um dos mais importantes, sendo estudado por diversos autores (AMPOORTER et al., 2007;

FLORESTA, Curitiba, PR, v. 46, n. 3, p. 307 - 314, jul. / set. 2016

Sampietro, J. A.; Lopes, E. da S.

ISSN eletrônico 1982-4688

DOI: $10.5380 /$ rf.v46i3.37217 
LABELLE; JAEGER, 2011; SEIXAS; SOUZA, 2007; SILVA et al., 2007; SILVA et al., 2008; AMPOORTER et al., 2010; SAMPIETRO; LOPES, 2011). Seixas e Souza (2007) relataram que em torno de $80 \%$ da compactação total de um solo de textura arenosa com uso de um trator equipado com carreta carregada de madeira ocorreram após cinco passadas, em um total de 20 passadas da máquina.

Em concordância, Silva et al. (2007) observaram, em testes com sucessivas passadas de um forwarder sobre um Latossolo Amarelo de textura argilo-arenosa, que a maior parte dos efeitos da compactação do solo foi manifestada por apenas quatro passadas da máquina. Resultados semelhantes também foram observados por Ampoorter et al. (2010), que verificaram que poucas passadas de um skidder em solos de diferentes texturas ocasionaram grande parte da compactação, com efeitos em solos argilosos maiores do que nos arenosos.

Diante do exposto, percebe-se que o conhecimento das propriedades físicas é fundamental para a tomada de decisão quanto ao manejo do solo e adequação do tipo de maquinário e tráfego para cada situação específica. Entretanto, procedimentos amostrais baseados na estatística clássica muitas vezes apresentam limitações quando se procura caracterizar a distribuição espacial de alguma propriedade estudada, pois somente a informação dada pela variância é insuficiente para explicar as relações envolvidas, devendo-se, para tal, levar em consideração a distância entre as observações (VIEIRA, 2000).

Dessa forma, pode ser empregada a geoestatística com o intuito de descrever o padrão da variabilidade espacial da propriedade medida. Com a geoestatística, a partir de interpoladores obtidos por krigagem, é possível gerar mapas de isolinhas do atributo analisado, e com o conhecimento do comportamento espacial de determinadas situações, podem-se monitorar aspectos ligados à conservação da estrutura do solo, permitindo a otimização dos sistemas de produção.

Dentre os poucos estudos que analisaram espacialmente o impacto das operações de colheita da madeira sobre o solo, destaca-se o trabalho de Lima et al. (2008), que avaliaram a compactação de um Latossolo Vermelho-Amarelo de textura muito argilosa em trilhas antes e após a passagem de um feller buncher e de um skidder. Os autores verificaram que a resistência do solo à penetração apresentou variabilidade espacial em relação às diferentes condições impostas e profundidades do solo, sendo que a maior compactação ocorreu nas camadas superficiais do solo. Shaw e Carter (2002), estudando três sítios com solos de diferentes texturas, constataram que, apesar de as propriedades físicas do solo terem sido alteradas, as operações de colheita da madeira não causaram elevado aumento na variabilidade espacial das propriedades físicas do solo, indicando que medidas para minimizar a compactação do solo são difíceis de serem implementadas, devido à especificidade de cada situação.

Com base nas informações citadas, este trabalho objetivou avaliar o impacto e a extensão em que a resistência do solo à penetração em um Cambissolo Húmico (CHa) foi afetada pelo tráfego de máquinas de colheita da madeira em povoamentos de Pinus taeda L., com uso de métodos geoestatísticos para determinação da dependência e variabilidade espacial.

\section{MATERIAL E MÉTODOS}

O trabalho foi conduzido em áreas operacionais de colheita da madeira de Pinus taeda L. em uma empresa florestal localizada na região norte do estado de Santa Catarina. Segundo Köppen, o clima da região apresenta-se como $\mathrm{Cfb}$, com temperatura média anual de $19,7^{\circ} \mathrm{C}$ e precipitação média anual entre 1.600 e $1.700 \mathrm{~mm}$. Altitude média de $530 \mathrm{~m}$ e localização geográfica na latitude de $26^{\circ} 42^{\prime} 52^{\prime}$ ' S e longitude de $49^{\circ} 29^{\prime} 00^{\prime} \mathrm{W}$.

A área de estudo foi utilizada no passado para fins de produção agropecuária, sendo posteriormente implantados povoamentos de Pinus taeda L., que no momento da colheita da madeira apresentavam 35 anos de idade. A população média por hectare foi de 442 árvores, com área basal média de $45,82 \mathrm{~m}^{2}$.ha ${ }^{-1}$, volume médio total de $654,35 \mathrm{~m}^{3} \cdot \mathrm{ha}^{-1}$ e peso médio individual das árvores de 1,48 toneladas.

O relevo foi classificado como suave ondulado, enquanto o solo como Cambissolo Húmico Alumínico típico (CHa) de textura franco-argilo-arenosa, horizonte A húmico, com teores médios de 244, 116 e $640 \mathrm{~g} \cdot \mathrm{kg}^{-1}$ de argila, silte e areia, respectivamente. Apresentou densidade e teor médio de carbono orgânico de 1,06 Mg.m $\mathrm{m}^{-3}$ e $19,86 \mathrm{~g} \cdot \mathrm{dm}^{-3}$, respectivamente, até os $0,50 \mathrm{~m}$ de profundidade.

$\mathrm{O}$ sistema de colheita da madeira utilizado foi o de árvores inteiras (full-tree), composto pelos tratores florestais feller buncher, skidder e harvester. Neste estudo, foi avaliado o tráfego dos tratores florestais feller buncher e skidder no interior do povoamento florestal. O feller buncher era da marca Caterpillar, modelo 522, com peso operacional de 30,4 $\mathrm{t}$ e rodados de esteiras com dimensões de $0,6 \times 4,8 \mathrm{~m}$. O skidder era da marca Caterpillar, modelo 545, com peso operacional de $18,2 \mathrm{t}$, tração $4 \times 4$, rodados de pneus de $0,8 \mathrm{~m}$ de largura, inflados com pressão de $290 \mathrm{kPa}$, sendo os dianteiros recobertos com semiesteiras.

Para avaliar os efeitos das diferentes intensidades de tráfego das máquinas nas áreas selecionadas, foi realizada inicialmente a remoção de toda a madeira das áreas sem haver a interferência de tráfego, prosseguindo com a distribuição de parcelas amostrais de $5 \times 40 \mathrm{~m}$ em cada tratamento analisado (Figura 1). Cada parcela 
correspondeu a uma simulação de intensidade de tráfego (tratamento), sendo que nas simulações as máquinas trafegaram com a mesma carga sobre a trilha de passagem dentro da parcela.

Durante as simulações, o feller buncher trafegou somente uma vez na área experimental, enquanto o skidder trafegou entre 1 e 15 vezes no mesmo recalque (rastro do feller buncher), sempre com a mesma carga de arraste (aproximadamente 5,90 t), numa velocidade média de $6,5 \mathrm{~km} \cdot \mathrm{h}^{-1}$, sendo que em cada passada representou somente uma viagem de ida da máquina. A umidade gravimétrica média do solo no momento dos ensaios era de 0,445 kg. $\mathrm{kg}^{-1}$, sendo acima da capacidade de campo (água retida no solo sob tensão de $10 \mathrm{kPa}$ ), que era, em média, de $0,293 \mathrm{~kg} \cdot \mathrm{kg}^{-1}$. A descrição e a abreviatura utilizada em cada tratamento encontram-se na tabela 1.

Tabela 1. Descrição dos tratamentos avaliados.

Table 1. Description of evaluated treatments.

\begin{tabular}{ll}
\hline Tratamentos & Descrição \\
\hline FB & 1 passada do feller buncher \\
FB + 1SD & 1 passada do feller buncher +1 passada do skidder \\
FB + 3SD & 1 passada do feller buncher +3 passadas do skidder \\
FB + 5SD & 1 passada do feller buncher +5 passadas do skidder \\
FB + 10SD & 1 passada do feller buncher +10 passadas do skidder \\
FB +15 SD & 1 passada do feller buncher +15 passadas do skidder \\
\hline
\end{tabular}

As leituras de resistência do solo à penetração (RP) foram realizadas in situ nas trilhas de passagem dos rodados das máquinas e transversalmente em intervalos de 0,25 até $1,00 \mathrm{~m}$, bem como entre os rodados, perfazendo uma malha de $5 \times 20 \mathrm{~m}$, totalizando 55 pontos por tratamento e 330 pontos amostrais totais (Figura 1). Embora tenham sido obtidos dados de 0,01 $\mathrm{m}$ até $0,80 \mathrm{~m}$ de profundidade, para a krigagem os dados foram agrupados em camadas com valores médios a cada $0,05 \mathrm{~m}$ de profundidade. A RP foi medida com o uso de um penetrógrafo eletrônico digital, da marca Eijkelkamp, modelo 06.15.SA, equipado com uma ponta em forma de cone com ângulo de vértice de $60^{\circ}$ e base de $1 \mathrm{~cm}^{2}$ (11,28 $\mathrm{mm}$ de diâmetro nominal), com a velocidade de penetração controlada em $2 \mathrm{~cm} \cdot \mathrm{s}^{-1}$.

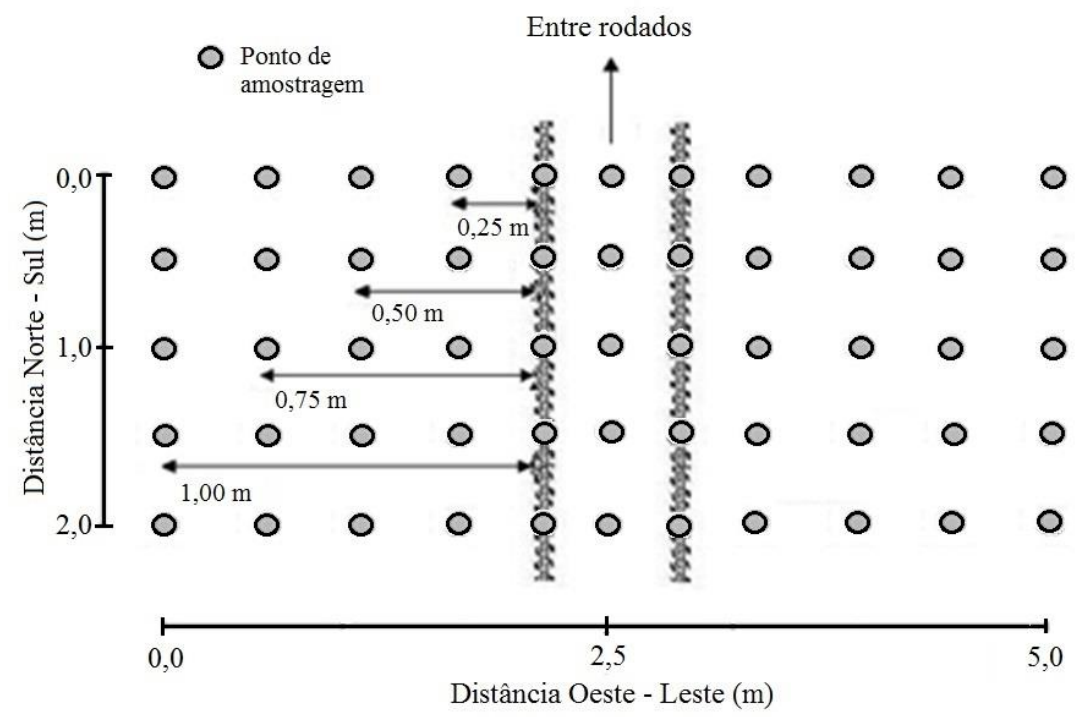

Figura 1. Esquema dos pontos amostrados de resistência à penetração em cada tratamento.

Figure 1. Design of measure points of penetration resistance sampled in which treatment.

Foi utilizada estatística descritiva para estudar a tendência e dispersão dos dados, bem como a forma de distribuição em cada tratamento, sendo verificada a normalidade dos dados pelo teste de Kolmogorov-Smirnov a 5\% de significância. A dependência espacial foi avaliada por técnicas de geoestatística com base nas pressuposições de estacionaridade da hipótese intrínseca, em que a variância da diferença depende somente da distância entre os pontos amostrais e não da posição em que eles se encontram, além de análise de semivariogramas utilizando-se o software GS+ 9,0 (ROBERTSON, 1998).

Para cada tratamento foram testados os ajustes de semivariogramas do tipo esférico, exponencial, linear e gaussiano. A escolha do melhor modelo teórico foi por meio do modelo de maior coeficiente de determinação $\left(\mathrm{R}^{2}\right)$ e grau de dependência espacial (GDE), usando-se a técnica de validação cruzada, sendo utilizados $25 \%$ dos

FLORESTA, Curitiba, PR, v. 46, n. 3, p. 307 - 314, jul. / set. 2016.

Sampietro, J. A.; Lopes, E. da S.

ISSN eletrônico 1982-4688

DOI: $10.5380 /$ rf.v46i3.37217 
dados para a validação e, também, calculado o coeficiente de regressão. Para análise do GDE, utilizou-se a seguinte equação: $\mathrm{C} /(\mathrm{Co}+\mathrm{C})$, em que $\mathrm{C}$ é a "contribuição" e significa a diferença entre o patamar $(\mathrm{Co}+\mathrm{C})$ e o efeito pepita (Co); Co é o efeito pepita; e Co+C é o patamar. O GDE mostra-se forte (GDE $\geq 0,75$ ), moderado $(0,25 \leq \mathrm{GDE}<0,75)$ e baixo (GDE < 0,25). Além disso, também foi determinado o alcance $(\mathrm{m})$, o qual indica o limite da dependência espacial da propriedade avaliada, isto é, determinações feitas em distâncias maiores que o alcance têm distribuição espacial aleatória e, assim, são independentes entre si, podendo ser aplicada a estatística clássica. Ao final, com a determinação do semivariograma e havendo dependência espacial entre os dados, prosseguiu-se com interpolação pelo método de krigagem do tipo ordinária e elaboração de mapas de isolinhas, estimando os valores de RP em locais não medidos.

\section{RESULTADOS E DISCUSSÃO}

Na tabela 2 são apresentados os valores de média, mediana, amplitude, coeficiente de variação (\%), assimetria, curtose, mínimo, máximo e teste de normalidade para a resistência à penetração (MPa) nos diferentes tratamentos avaliados.

A estatística descritiva mostrou que houve uma grande variação e amplitude dos dados, sendo que para todos os tratamentos, exceto FB + 1SD, o coeficiente de variação (CV\%) foi maior que 30\% (Tabela 2). Para Gomes e Garcia (2002), a variabilidade de um atributo pode ser classificada por meio dos valores de CV\% como baixo ( $\leq 10 \%)$, médio $(10 \%-20 \%)$, alto $(20 \%-30 \%)$ e muito alto (> 30\%). Portanto, a alta variação dos dados pode ser atribuída à alta variabilidade do solo e por outros fatores que interferiram na determinação do atributo em condições de campo, como a presença de pedras e resíduos da colheita de madeira (galhos, cascas, acículas etc.), raízes e sub-bosque que se formou abaixo do povoamento.

Tabela 2. Estatística descritiva para a resistência do solo à penetração (MPa) nos diferentes tratamentos avaliados.

Table 2. Summary statistics for soil penetration resistance (MPa) in the different treatments evaluated.

\begin{tabular}{lrrrrrrrrr}
\hline Tratamento & Média & Mediana & Amplitude & CV\% & Assimetria & Curtose & Mín & Máx. & d \\
\hline FB & 1,38 & 1,33 & 2,27 & 30,64 & $-0,09$ & $-0,24$ & 0,32 & 2,59 & $0,07^{\mathrm{ns}}$ \\
FB+1SD & 1,25 & 1,25 & 1,62 & 26,95 & $-0,32$ & $-0,08$ & 0,30 & 1,93 & $0,05^{\mathrm{ns}}$ \\
FB+3SD & 1,35 & 1,35 & 2,40 & 35,75 & 0,09 & $-0,11$ & 0,26 & 2,66 & $0,04^{\mathrm{ns}}$ \\
FB+5SD & 1,46 & 1,47 & 2,70 & 34,39 & $-0,04$ & 0,15 & 0,32 & 3,01 & $0,07^{\mathrm{ns}}$ \\
FB+10SD & 1,60 & 1,65 & 2,80 & 35,58 & $-0,11$ & $-0,05$ & 0,28 & 3,08 & $0,05^{\mathrm{ns}}$ \\
FB+15SD & 1,69 & 1,65 & 3,35 & 39,73 & 0,62 & 0,77 & 0,38 & 3,74 & 0,10 \\
\hline
\end{tabular}

$\mathrm{FB}=1$ passada do feller buncher $; \mathrm{FB}+1 \mathrm{SD}=1$ passada do feller buncher +1 passada do skidder $; \mathrm{FB}+3 \mathrm{SD}=1$ passada do feller buncher +3 passadas do skidder $; \mathrm{FB}+5 \mathrm{SD}=1$ passada do feller buncher +5 passadas do skidder $; \mathrm{FB}+10 \mathrm{SD}=1$ passada do feller buncher +10 passadas do skidder $; \mathrm{FB}+15 \mathrm{SD}=1$ passada do feller buncher +15 passadas do skidder; CV\% = coeficiente de variação; Mín = valor mínimo observado; Máx = valor máximo observado; $d=$ teste de normalidade de Kolmogorov-Smirnov a 5\% de significância.

Pode ser observado também que os maiores valores de resistência do solo à penetração ocorreram após a condição de maior tráfego (FB + 15SD), ocorrendo a compactação gradualmente, conforme mais intenso ia sendo o tráfego imposto pelas máquinas estudadas. Além disso, esse foi o tratamento que apresentou maior amplitude e variação, não havendo normalidade no conjunto de dados. Entretanto, o que mais importa, conforme Isaaks e Srivastava (1989), não é os dados apresentarem normalidade e sim a ocorrência ou a não ocorrência do efeito proporcional, ou seja, que a média e a variabilidade dos dados sejam constantes na área experimental. Isso não foi constatado no presente trabalho, uma vez que todos os semivariogramas de todos os tratamentos apresentaram patamares definidos, e a distribuição não apresentou caudas muito alongadas, o que, de certa forma, poderia comprometer as estimativas da krigagem, devido a elas serem baseadas em valores médios.

É importante ressaltar que valores de resistência à penetração acima de $2 \mathrm{MPa}$ foram observados em todos tratamentos, sendo esse o limite considerado potencialmente crítico ao desenvolvimento radicular das plantas (GREACEN; SANDS, 1980), sugerindo que a compactação poderá interferir no desenvolvimento de futuras rotações, caso medidas de preparo e mobilização do solo não sejam tomadas. No entanto, isso é agravado pela observação de haver valores acima de $3 \mathrm{MPa}$, que, conforme Zou et al. (2000), é o valor teórico no qual passa a ser restritivo o desenvolvimento radicular de espécies florestais.

Os parâmetros de ajuste dos semivariogramas (Tabela 3) possibilitaram a análise da presença ou não de dependência espacial, sendo possível observar que para todos os tratamentos avaliados houve predominância do ajuste de semivariogramas do tipo gaussiano, como ilustrado na figura 2 . O presente resultado entra em contraste com outros resultados da literatura, nos quais os modelos esférico e exponencial, geralmente, são aqueles que mais se ajustam a dados advindos de atributos do solo (SHAW; CARTER, 2002; LIMA et al., 2008; ROSA FILHO et al., 2011; RODRIGUES, et al., 2015). 
Tabela 3. Estimativa dos parâmetros dos modelos teóricos ajustados para a resistência à penetração dos diferentes tratamentos.

Table 3. Estimated parameters of adjusted models for penetration resistance of different treatments.

\begin{tabular}{llrrrrrc}
\hline Tratamentos & Modelo & Co & Co+C & Alcance (m) & $\mathbf{R}^{\mathbf{2}}$ & GDE & $\begin{array}{l}\text { Coef. regressão } \\
\text { validação cruzada }\end{array}$ \\
\hline FB & Gaussiano & 0,0373 & 0,2556 & 0,89 & 0,997 & 0,854 & 0,770 \\
FB + 1SD & Gaussiano & 0,0265 & 0,1620 & 0,93 & 0,993 & 0,836 & 0,708 \\
FB + 3SD & Gaussiano & 0,0638 & 0,2826 & 0,83 & 0,999 & 0,774 & 1,003 \\
FB + 5SD & Gaussiano & 0,0695 & 0,3780 & 0,99 & 0,997 & 0,816 & 0,838 \\
FB + 10SD & Gaussiano & 0,0580 & 0,4200 & 0,83 & 0,996 & 0,862 & 0,928 \\
FB + 15SD & Gaussiano & 0,1010 & 1,4140 & 2,12 & 0,985 & 0,929 & 0,896 \\
\hline C
\end{tabular}

validação cruzada $=$ coeficiente de regressão da validação cruzada

Em todos os tratamentos avaliados, os ajustes dos semivariogramas mostraram haver estacionariedade, isto é, o tamanho da área amostrada foi suficiente para expressar toda a variabilidade dos valores de resistência à penetração, sendo que os valores de alcance $(\mathrm{m})$ variaram de 0,83 a 2,12 $\mathrm{m}$. Além disso, é possível verificar altos valores de $\mathrm{R}^{2}$ e coeficiente de regressão da validação cruzada, demonstrando, apesar do alto GDE, bom ajustes.
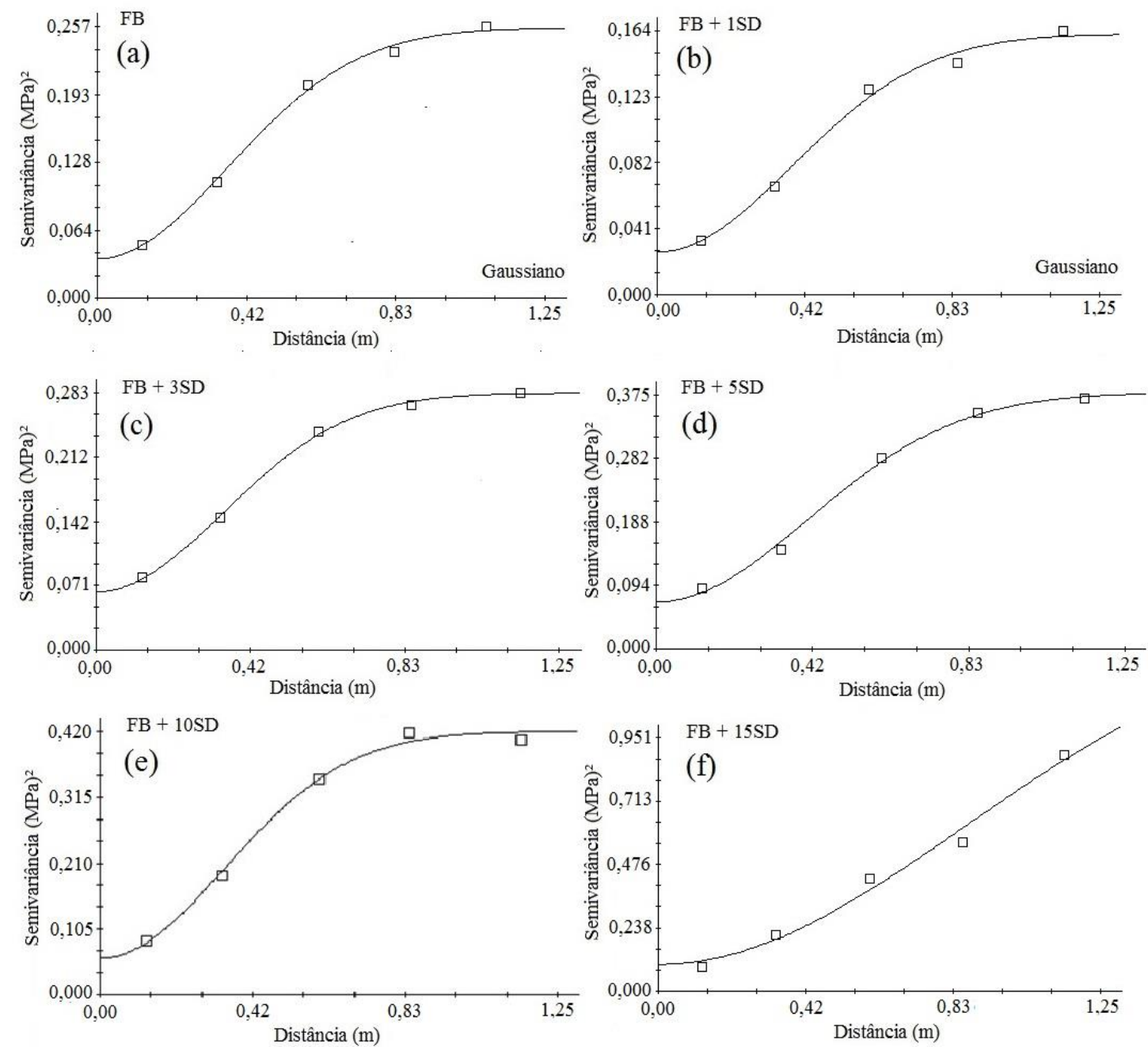

Figura 2. Semivariogramas ajustados para a resistência à penetração de diferentes intensidades de tráfego de máquinas de colheita florestal em um Cambissolo Húmico Alumínico típico (CHa). (a) FB; (b) FB + 1SD; (c) FB + 3SD; (d) FB + 5SD; (e) FB + 10SD; (f) FB + 15SD.

Figure 2. Adjusted semivariograms to penetration resistance of different traffic intensities of logging machines in a Humic Cambisol (HC). (CHa). (a) FB; (b) FB + 1SD; (c) FB + 3SD; (d) FB + 5SD; (e) FB + 10SD; (f) FB + 15SD. 
Com isso, fica evidente a grande aplicabilidade da determinação da RP in situ, pois, além de permitir a obtenção de dados de forma fácil e rápida, muitas vezes pode ser mais sensível que relações massa por volume na detecção de alterações no solo (SHAW; CARTER, 2002). Contudo, deve-se ter cautela no seu emprego, uma vez que varia em função de outras propriedades, como densidade, umidade, textura, ângulo de atrito e coesão do solo (REICHERT et al., 2010).

Em relação à estrutura dos semivariogramas ajustados para a RP dos diferentes tratamentos (Figura 2), é possível verificar semelhanças entre eles, o que pode ser associado ao fato de que, nas simulações de tráfego, as sucessivas passadas em cada tratamento ocorreram sempre em mesma trilha. Assim, com a intensificação do tráfego das máquinas, cada vez mais os efeitos tenderam a ser cumulativos e tenderam a alterar a RP do solo em mesmo sentido e extensão.

Após os ajustes dos modelos teóricos e a definição da dependência espacial da resistência do solo à penetração para todos os tratamentos, realizou-se a krigagem ordinária dos dados, obtendo-se dessa forma os mapas de isolinhas de RP (Figura 3).

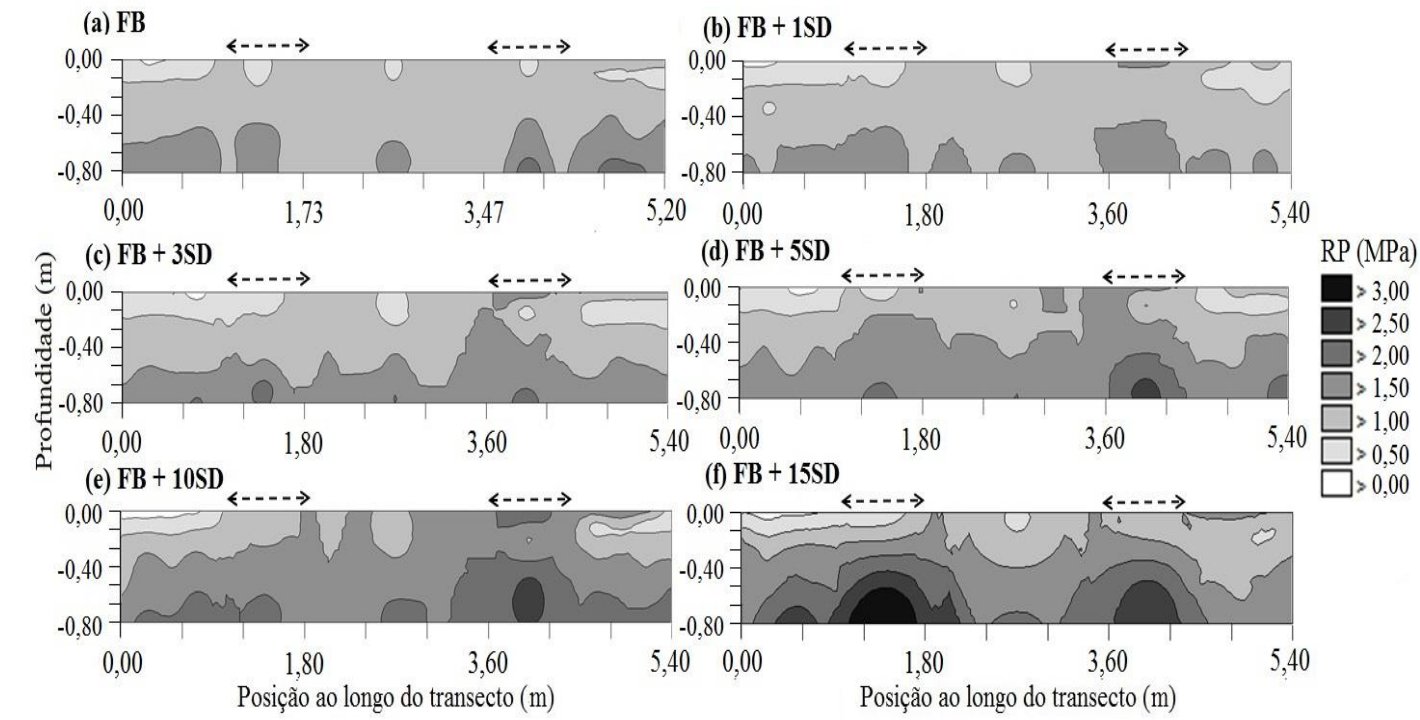

Figura 3. Efeito dos tratamentos ao longo do perfil do Cambissolo Húmico Aluminíco típico (CHa) em isolinhas de resistência à penetração. (a) FB; (b) FB + 1SD; (c) FB + 3SD; (d) FB + 5SD; (e) FB + 10SD; (f) FB + 15SD. A legenda indica os valores de resistência à penetração em $\mathrm{MPa}$. As setas indicam a posição da linha de passagem dos rodados.

Figure 3. Effect of treatments along of the profile of Humic Cambisol (HC) in isolines of penetration resistance. (a) FB; (b) FB + 1SD; (c) FB + 3SD; (d) FB + 5SD; (e) FB + 10SD; (f) FB + 15SD. The legend indicates values of penetration resistance in $\mathrm{MPa}$. The arrows indicate the position of the wheel tracks.

Por meio das plotagens, é possível observar que, conforme aumentou o número de passadas das máquinas, houve alteração em todo o perfil do solo, sendo, primeiramente, impactadas as camadas mais profundas de solo nas passadas iniciais (até FB+3SD) e depois toda a extensão do solo que foi avaliada. Isso deixou ainda mais evidente a ação do tráfego das máquinas de colheita da madeira sobre o solo, mostrando que, de fato, o tratamento $\mathrm{FB}+15 \mathrm{SD}$ foi o causador de maior impacto sobre a resistência à penetração.

Entretanto, é importante, ainda, observar que altos valores de resistência à penetração já ocorreram no tratamento FB + 5SD (Figura 3), evidenciando que a partir desse nível de tráfego as condições limitantes ao crescimento radicular das plantas começam a ser cada vez maiores, conforme aumenta o tráfego das máquinas.

O aumento gradativo da compactação conforme o tráfego pode ser ainda explicado, em parte, pela condição de umidade do solo no momento das simulações de tráfego das máquinas, que era, em média, de $0,445 \mathrm{~kg} \cdot \mathrm{kg}^{-1}$, estando acima da capacidade de campo. Portanto, pode-se inferir que, na presente situação, a capacidade de suporte do solo estava baixa, pois, com umidade alta, este é o principal fator que governa a quantidade de deformação que poderá ocorrer no solo (BRAIDA et al., 2010; REICHERT et al., 2010; SAMPIETRO et al., 2015; SILVA; CABEDA, 2006).

Em condição de baixa umidade, há maior coesão entre as partículas do solo, devido a não haver água suficiente para formar filmes sobre elas, fazendo com que a compactação tenda a não ser elevada. Contudo, 
conforme a umidade aumenta, os filmes de água sobre as partículas do solo expandem-se, de modo que a coesão entre as partículas diminui e a resistência do solo se torna menor em relação às aplicações de forças externas. Assim, a deformação plástica passa a ser o processo dominante, resultando na formação de sulcos no solo pelos rodados das máquinas. Por outro lado, em alta umidade, embora a compactação tenda a ser menor, pode ocorrer "fechamento" de poros e destruição de sua continuidade, levando a problema em termos de infiltração de água e trocas gasosas (GREACEN; SANDS, 1980; REICHERT et al., 2010).

A sobreposição de passadas das máquinas agravou os impactos causados sobre o solo, devido ao acúmulo de cargas aplicadas sobre sua superfície ter sido distribuído ao longo do perfil, em função das tensões e das deformações resultantes. Estas tiveram maior ou menor intensidade, conforme as características físicomecânicas do solo, resultando em alterações em profundidade no perfil do solo, bem como horizontalmente, devido às tensões cisalhantes (HORN et al., 2007; LAMANDÉ; SCHJØNNING, 2011a; LAMANDÉ; SCHJØNNING, 2011b; REICHERT et al., 2010).

Resultados semelhantes foram relatados por Lima et al. (2008), que avaliaram o efeito espacial do tráfego de um sistema de colheita composto por feller buncher e skidder sobre um Latossolo Vermelho-Amarelo muito argiloso e concluíram que o tráfego da máquina de corte (feller buncher) proporcionou menor incremento da RP em relação ao skidder, com menores valores no sentido horizontal do perfil e maiores em profundidade. Outros trabalhos, como o de Ampoorter et al. (2010) e Rodrigues et al. (2015), também analisaram os efeitos do tráfego das máquinas de colheita da madeira de forma espacializada, relatando resultados semelhantes em outras condições de solo e sistema de colheita.

Em geral, em solos florestais o processo de compactação apresenta uma dinâmica física diferente em relação ao observado em outros sistemas de manejo, pois, diferentemente das pastagens e lavouras, as árvores apresentam ciclos longos, sendo sujeitas a variações climáticas durante vários anos, com suas raízes impondo forças mecânicas sobre o solo. Além disso, há o crescente emprego de máquinas de grande porte nas operações de colheita da madeira, trafegando indiscriminadamente e sem controle em condições inadequadas de umidade, com aumento do peso e da quantidade das cargas transportadas, além da derrubada, arraste e levantamento de grandes árvores, contribuindo para que ocorram sérios problemas de compactação em áreas florestais.

Dessa forma, o trabalho demonstrou a importância de melhor compreender os efeitos do tráfego das máquinas de colheita da madeira sobre as propriedades físicas do solo utilizando a metodologia da geoestatística. Com essa tomada de decisão, o planejamento das operações florestais pode ser realizado para posterior manejo da minimização dos danos ocasionados pela compactação do solo, apresentando assim sustentabilidade e melhoria das práticas para a produção de madeira. Com base nisso, os efeitos negativos do tráfego das máquinas sobre o solo podem ser analisados de forma mais clara, podendo-se observar a extensão das alterações sofridas em relação às condições impostas e ao manejo aplicado ao solo, propiciando a escolha de medidas mitigadoras.

\section{CONCLUSÕES}

Os resultados e discussões desta pesquisa permitiram concluir que:

- As sucessivas passadas do feller buncher e do skidder provocaram alterações na resistência mecânica do solo à penetração, com maiores alterações com o aumento da intensidade de tráfego das máquinas.

- A maior parte do perfil do solo foi impactado pelo tráfego das máquinas, podendo-se verificar efeitos até às camadas mais profundas e distantes das trilhas de passagem dos rodados.

- A metodologia da geoestatística permitiu determinar a extensão dos efeitos do tráfego, podendo servir de subsídio para melhoria nas práticas de manejo do solo e planejamento das operações florestais.

\section{AGRADECIMENTOS}

À empresa florestal, por ceder a área para a realização do estudo, e também ao prof. dr. Marcos Benedito Schimalski, da Universidade do Estado de Santa Catarina, pelo auxílio nas análises realizadas.

\section{REFERÊNCIAS}

AMPOORTER, E.; GORIS, R.; CORNELIS, W. M.; VERHEYEN, K. Impact of mechanized logging on compaction status of sandy forest soils. Forest Ecology and Management, v. 241, p. 162-174, 2007.

AMPOORTER, E.; NEVEL, V. L.; VOS, D. B.; VERHEYEN, K. Assessing the effects of initial soil characteristics, machine mass and traffic intensity on forest soil compaction. Forest Ecology and Management, v. 260, p. 1664-1676, 2010.

BRAIDA, J. A.; REICHERT, J. M.; REINERT, D. J.; VEIGA, M. da. Teor de carbono orgânico e a susceptibilidade à compactação de um Nitossolo e um Argissolo. Revista Brasileira de Engenharia Agrícola e 
Ambiental, v. 14, p. 131-139, 2010.

GOMES, F. P.; GARCIA, C. H. Estatística aplicada a experimentos agronômicos e florestais. Piracicaba: ESALQ, 2002, 309 p.

GREACEN, E. L.; SANDS, R. Compaction of forest soils: a review. Australian Journal of Soil Research, v. 18, p. 163-189, 1980.

HORN, R.; VOSSBRINK, J.; PETH, S.; BECKER, S. Impact of modern forest vehicles on soil physical properties. Forest Ecology and Management, v. 248, p. 56-63, 2007.

ISAAKS, E. H.; SRIVASTAVA, R. M. An introduction to applied geoestatistics. New York: Oxford University, 1989. $561 \mathrm{p}$.

LABELLE, E. R.; JAEGER; D. Soil compaction caused by caused by cut-to-legth forest operations and possible short-term natural rehabilitation of soil density. Soil Science of America Journal, v. 75, p. 2314-2329, 2011.

LAMANDÉ, M.; SCHJØNNING, P. Transmission of vertical stress in a real soil profile. Part I: Site description, evaluation of the Söhne model, and the effect of topsoil tillage. Soil and Tillage Research, v. 114, p. 57-70, 2011 a.

LAMANDÉ, M.; SCHJØNNING, P. Transmission of vertical stress in a real soil profile. Part II: Effect of tyre size, inflation pressure and wheel load. Soil and Tillage Research, v. 114, p. 71-77, 2011b.

LIMA, J. S. S.; OLIVEIRA, P. C.; OLIVEIRA, R. B.; XAVIER, A. C. Métodos geoestatísticos no estudo da resistência do solo à penetração em trilha de tráfego de tratores na colheita de madeira. Revista Árvore, v. 32, n. 5, p. 931-938, 2008.

LOPES, S. E.; FERNANDES, H. C.; MACHADO, C. C.; RINALDI, P. C. N.; SILVEIRA, J. C. M. Compactação de um latossolo submetido ao tráfego do "Clambunk". Scientia Forestalis, Piracicaba, n. 72, p. 23-28, 2006.

REICHERT, J. M.; REINERT, D. J.; SUZUKI, L. E. A. S.; HORN, R. Mecânica do Solo. In: JONG VAN LIER, Q. Física do Solo. Viçosa, MG: Sociedade Brasileira de Ciência do Solo, p. 29-102, 2010.

ROBERTSON, G. P. GS+ geostatistics for the environmental sciences: GS+ user's guide. Plainwell: Gamma Design Software, 1998. 152 p.

RODRIGUES, C. K.; LOPES, E. S.; MÜLLER, M. M. L.; GENÚ, A. M. Variabilidade espacial da compactação de um solo submetido ao tráfego de harvester e forwarder. Scientia Forestalis, v. 43, p. 387-394, 2015.

ROSA FILHO, G.; CARVALHO, M. P.; MONTANARI, R.; SILVA, J. M.; SIQUEIRA, G. M.; ZAMBIANCO, E. C. Variabilidade espacial de propriedades dendrométricas do eucalipto e de atributos físicos de um Latossolo Vermelho. Bragantia, v. 70, p. 439-446, 2011.

SAMPIETRO, J. A.; LOPES, E. S. Compactação de Cambissolo e Neossolo submetidos a diferentes intensidades de tráfego de feller buncher e skidder. Scientia Forestalis, v. 39, p. 265 - 272, 2011.

SAMPIETRO, J. A.; LOPES, E. S. Compactação causada pelo tráfego de feller buncher e skidder em um neossolo regolítico sob distintas umidades. Ciência Florestal, v. 25, n. 1, p. 239-248, 2015.

SEIXAS, F.; SOUZA, C. R. Avaliação e efeito da compactação do solo devido à frequência de tráfego na produção de madeira de eucalipto. Revista Árvore, v. 31, n. 6, p. 1047-1052, 2007.

SHAW, J. N.; CARTER, E. A. Timber harvesting effects on spatial variability of southeastern U.S. Piedmont soil properties. Soil Science, v. 167, p. 289-302, 2002.

SILVA, A. J. N.; CABEDA, M. S. V. Compactação e compressibilidade do solo sob sistemas de manejo e níveis de umidade. Revista Brasileira de Ciência do Solo, v. 30, p. 921-930, 2006.

SILVA, S. R.; BARROS, N. F.; COSTA, L. M.; LEITE, F. P. Soil compaction and eucalyptus growth in response to fowarder traffic intensity and load. Revista Brasileira de Ciência do Solo, v. 32, p. 921-932, 2008.

SILVA, S. R.; BARROS, N. F.; COSTA, L. M.; MENDONÇA, E. S.; LEITE, F. P. Alterações do solo influenciadas pelo tráfego e carga de um forwarder nas entrelinhas de uma floresta de eucalipto. Revista Brasileira de Ciência do Solo, v. 31, p. 371-377, 2007.

VIEIRA, S. R. Geoestatística em estudos de variabilidade espacial do solo. In. NOVAES, R. F.; ALVAREZ V.; SCHAEFER, C. E. G. R. Tópicos em ciências do solo. Viçosa, MG: Sociedade Brasileira de Ciência do Solo, p. 2-54, 2000.

ZOU, C.; SANDS, R.; BUCHAN, G.; HUDSON, I. Least limiting water range: A potential indicator of physical quality of forest soils. Australian Journal of Soil Research, v. 28, p. 947-958, 2000. 